\title{
Taurine Behaves as an Osmolyte in Madin-Darby Canine Kidney Cells Protection by Polarized, Regulated Transport of Taurine
}

\author{
Shinichi Uchida, Takeshi Nakanishi, * H. Moo Kwon, Agnes S. Preston, and Joseph S. Handler \\ Division of Nephrology, Department of Medicine, Johns Hopkins University School of Medicine, Baltimore, Maryland 21205; \\ and ${ }^{*}$ Fifth Department of Internal Medicine, Hyogo College of Medicine, Hyogo, Japan
}

\begin{abstract}
Using a clonal growth assay, we demonstrated that taurine, a nonperturbing osmolyte accumulated in kidney medulla, brain, and some other tissues of hypertonic experimental animals can function as a nonperturbing osmolyte in Madin-Darby canine kidney (MDCK) cells. The taurine content of hypertonic MDCK cells is twice that of isotonic MDCK cells (isotonic 160 $\mathrm{nmol} / \mathrm{mg}$ protein; hypertonic $320 \mathrm{nmol} / \mathrm{mg}$ protein). Therefore we studied taurine transport in MDCK cells grown on porous supports and then studied the effect of hypertonicity which is known to elicit increased uptake of some other nonperturbing osmolytes by MDCK cells. Basal uptake exceeded apical uptake, with $K_{\mathrm{m}}$ and $V_{\max }$ of $56 \mu \mathrm{M}$ and $933 \mathrm{pmol} / \mathrm{min} \cdot \mathrm{mg}$ protein on the basal surface and $10 \mu M$ and $50 \mathrm{pmol} / \mathrm{min} \cdot \mathrm{mg}$ protein on the apical surface. On both surfaces, virtually all taurine uptake was $\mathrm{Na}^{+}$and $\mathrm{Cl}^{-}$dependent. $24 \mathrm{~h}$ after cells were shifted to hypertonic medium ( 500 mosmol/kg), taurine uptake doubled on the basolateral surface without change on the apical surface. The response to hypertonicity was the result of an increase in $V_{\max }$ without change in $K_{\mathrm{m}}$. There was no change in taurine efflux when cells were shifted from isotonic to hypertonic medium. When cells adapted to hypertonic medium were shifted to isotonic medium, a large transient basolateral efflux of taurine occurred within $10 \mathrm{~min}$. We conclude that taurine can function as a nonperturbing osmolyte in MDCK cells and that tonicity-regulated taurine transport is a basolateral function in MDCK cells. (J. Clin. Invest. 1991. 88:656662.) Key words: chloride cotransport • colony-forming efficiency $\bullet$ cultured kidney cells $\bullet$ sodium cotransport
\end{abstract}

\section{Introduction}

When the renal medulla is hypertonic, the cells in the medulla contain high concentrations of nonperturbing small organic solutes (osmolytes) $(1,2)$. By accumulating nonperturbing osmolytes to balance extracellular hypertonicity, the cells are protected from the perturbing effects that would be caused by high intracellular concentrations of electrolytes (2). Sorbitol,

Portions of this study have appeared in abstract form (1990. J. Am. Soc. Nephrol. 1:708).

Address reprint requests to Dr. Handler, Division of Nephrology, Johns Hopkins University School of Medicine, 217 Hunterian, 725 N. Wolfe Street, Baltimore, MD 21205.

Received for publication 10 January 1991 and in revised form 26 March 1991

J. Clin. Invest.

(c) The American Society for Clinical Investigation, Inc.

0021-9738/91/08/0656/07 \$2.00

Volume 88, August 1991, 656-662 myo-inositol, betaine, and glycerophosphorylcholine have been identified as major osmolytes in the medulla, some kidney-derived cell lines (3), and in a variety of nonmammalian species whose cells are exposed to a hypertonic environment (2). Mardin-Darby canine kidney (MDCK) ${ }^{1}$ cells accumulate myo-inositol, betaine, and glycerophosphorylcholine when cultured in hypertonic medium (3). The accumulation of myoinositol and betaine results from increased activity of their respective $\mathrm{Na}^{+}$-coupled transporters in cells with very low passive permeability to the osmolytes $(4,5)$. We report here observations indicating that taurine (2-aminoethanesulfonic acid) is a nonperturbing osmolyte for MDCK cells.

Taurine is a major free intracellular amino acid in many tissues. It is found in millimolar concentrations in brain, heart, eye, and liver (6). High intracellular taurine concentrations in tissues reported to have limited capacity for taurine biogenesis (7) indicate that taurine is probably taken up against a concentration gradient from extracellular fluid where its concentration is $\sim 50 \mu \mathrm{M}(8)$. $\mathrm{Na}^{+}$-dependent taurine transport has been well characterized in many tissues (9-16). The transporter has a far higher affinity for $\beta$-amino acids than for $\alpha$-amino acids (6), and is unusual in that chloride is also required $(13,17-20)$. The sodium and chloride requirement reflect a postulated stoichiometry of $2 \mathrm{Na}^{+}: 1 \mathrm{Cl}^{-}: 1$ taurine $(13,19-21)$. Such coupling would explain intracellular accumulation of taurine against a steep concentration gradient.

In the kidney, most filtered taurine is reabsorbed in the proximal tubule by a sodium- and chloride-coupled transporter that has been well characterized in brush border membrane vesicles (18-20). The activity of the cotransporter in the brush border of the proximal tubule contributes to whole-body homeostasis of taurine: activity increases in animals fed diets deficient in taurine- and sulfur-containing amino acids $(6,12$, $22)$. The cotransporter has not been identified in other segments of the nephron.

Osmolytes are accumulated by cells in hypertonic conditions and released when cells are shifted to an environment of lower osmolality. A few reports indicate that taurine is accumulated and released as though it were an osmolyte involved in cell volume regulation. The brains of rats made severely hypernatremic contained higher concentrations of taurine than the brains of rats maintained under isotonic conditions in most (23-25) but not all (26) studies. The hypertonic brains also contained some other well-established osmolytes $(25,26)$. When fish were shifted to a hypoosmotic environment $(14,27$, 28 ), they excreted taurine in their urine, reflecting taurine release from tissues (29). Ehrlich ascites tumor cells released taurine when shifted to a hypoosmotic solution $(15,17)$. Recently,

1. Abbreviations used in this paper: DIDS, 4,4'-diisothiocyanatostilbene-2,2'-disulfonic acid; MDCK, Madin-Darby canine kidney (cells); PCA, perchloric acid. 
taurine was identified as a major amino acid in the renal inner medulla of rats infused with $5 \% \mathrm{NaCl}(30)$, reaching a level $(65 \pm 6 \mathrm{mmol} / \mathrm{kg}$ protein) that was $40 \%$ higher than in controls. Furthermore, the same level of increased of taurine content was observed in the inner medulla when rats were prevented from drinking for $4 \mathrm{~d}$. The taurine content of the inner medulla returned to control levels after hydration (T. Nakanishi, unpublished results). Taurine transport in MDCK cells grown on plastic tissue culture dishes has been characterized recently (12), but the location of the transporter in the cells and regulation by hypertonicity was not examined.

In view of the evidence that taurine has the properties of a nonperturbing osmolyte (2) and is accumulated and released by some tissues, including renal medulla, as though it were an osmolyte, we examined the hypotheses that taurine could function as an osmolyte in MDCK cells and that, like the $\mathrm{Na}^{+} /$myoinositol and $\mathrm{Na}^{+}$/betaine cotransporters $(4,5)$, the taurine cotransporter in MDCK cells is regulated by hypertonicity. To test the hypotheses, we first tested whether taurine in the culture medium could rescue cells in hypertonic medium lacking other osmolytes. We next measured taurine content in MDCK cells in isotonic and hypertonic media, and studied the polarity and kinetic characteristics of taurine transport in MDCK cells cultured on a permeable filter support. Then we examined the uptake and release of taurine when MDCK cells were shifted from an isotonic to hypertonic medium or from a hypertonic to isotonic medium. We found that taurine is an osmolyte in MDCK cells and that taurine transport is primarily a basolateral function that is regulated very much like the transport of myo-isotonol and betaine, two other osmolytes accumulated by hypertonic MDCK cells.

\section{Methods}

Cell culture. MDCK cells were purchased from the American Type Culture Collection, Rockville, MD, and grown in defined medium, a 50:50 mixture of Dulbecco's modified Eagle's medium with $1 \mathrm{~g} /$ liter D-glucose and Coon's modified Ham's F-12 medium containing 10 $\mathrm{mM}$ Hepes, 5 pM triiodothyronine, $50 \mathrm{nM}$ hydrocortisone, $10 \mathrm{nM}$ $\mathrm{Na}_{2} \mathrm{SeO}_{3}$, transferin, $5 \mu \mathrm{g} / \mathrm{ml}$, insulin, $5 \mu \mathrm{g} / \mathrm{ml}$, prostaglandin $\mathrm{E}_{1}, 25$ $\mathrm{ng} / \mathrm{ml}, 2 \mathrm{mM}$ L-glutamine, penicillin, $100 \mathrm{IU} / \mathrm{ml}$, and streptomycin, $100 \mu \mathrm{g} / \mathrm{ml}(31)$. The defined medium routinely contained $200 \mu \mathrm{M}$ myo-inositol and $64 \mu \mathrm{M}$ choline, which support the accumulation of myo-inositol and glycerophosphorylcholine in MDCK cells in hypertonic medium $(3,32,33)$. In some experiments myo-inositol was deleted from the medium. Except where indicated, the defined medium did not contain taurine or betaine. Cells were carried on tissue culture plastic dishes.

Measurement of colony-forming efficiency. MDCK cells were seeded at a density of 200 cells per $10-\mathrm{cm}$ dish in isotonic defined medium with $10 \%$ nondialyzed serum. $1 \mathrm{~d}$ later, the medium was replaced with defined medium containing $10 \%$ dialyzed fetal bovine serum (FBS), with or without added myo-inositol or betaine or taurine, as indicated in Results. FBS was dialized against $24 \mathrm{vol}$ of Dulbecco's modified phosphate-buffered saline (PBS) using dialysis tubing with a molecular weight cutoff of 3,000 . Dialyzed FBS was nominally free of myo-inositol, betaine, and taurine. Colonies were allowed to grow for 1 wk without feeding. At this point, colonies were fixed in $10 \%$ Formalin in PBS (15 min), rinsed with distilled water, and stained in $1 \%$ toluidine blue 0 ( $15 \mathrm{~min}$, followed by water rinse). The number of colonies was then counted under a dissecting microscope. Only colonies with a diameter larger than $1 \mathrm{~mm}$ were counted (34-36).

Measurement of taurine content of cells grown in isotonic and hypertonic media. MDCK cells were seeded at confluent density on tissue culture-treated polycarbonate filters (Transwell, Costar, Cambridge, MA) in defined medium with $10 \%$ fetal bovine serum (Hazelton Biologics, Inc., Lenexa, KS). Serum was added to enhance cell attachment to the filter. $2 \mathrm{~d}$ after seeding, medium was replaced with defined medium without serum and cells were maintained without serum for 4 or $5 \mathrm{~d}$ until medium osmolarity was changed. The defined medium used to replace the medium containing FBS contained $50 \mu \mathrm{M}$ taurine. Cells were fed twice a week and on the day before the experiment by replacing the medium on both surfaces of the epithelium. In experiments where the acute effects of increased extracellular osmolarity were studied, cells were switched in a single step from isotonic defined medium (300 mosmol $/ \mathrm{kg}$ ) to medium made hypertonic $(500 \mathrm{mosmol} / \mathrm{kg})$ by addition of raffinose.

To measure taurine content, the cells were rinsed three times on both surface with PBS, and the filters with attached epithelia were cut out of the filter supports, and transferred to a liquid scintillation vial, containing $1 \mathrm{ml}$ of $7 \%$ perchloric acid (PCA) to extract intracellular taurine. After $2 \mathrm{~h}$ of incubation at room temperature on an orbital shaker, PCA was precipitated from the extracts by neutralizing with 1 $\mathrm{M} \mathrm{KOH}$. Taurine contents were measured using an analyzer (model L-8500, High Speed Amino Acid Analyzer, Hitachi Scientific Instruments, Mountain View, CA). Cell protein content was measured (Protein Assay kit, Bio-Rad Laboratories, Richmond, CA) after dissolving the PCA protein precipitate in $500 \mu \mathrm{l}$ of $0.25 \mathrm{NaOH}$.

Measurement of taurine transport. MDCK cells were prepared in the same way as in the taurine content experiment except that the defined medium did not contain taurine unless otherwise noted.

To measure taurine uptake into MDCK cells grown on filters, the cells were rinsed three times on both surfaces with PBS, and then incubated for $15 \mathrm{~min}$ at $37^{\circ} \mathrm{C}$ in preincubation solution $(150 \mathrm{mM} \mathrm{NaCl}$ or $150 \mathrm{mM}$ choline chloride, $5 \mathrm{mM} \mathrm{KCl}, 2 \mathrm{mM} \mathrm{CaCl}_{2}, 1 \mathrm{mM} \mathrm{MgCl}_{2}, 10$ $\mathrm{mM}$ Hepes/Tris (hydroxymethyl)-aminomethane, $\mathrm{pH}$ 7.4. This solution was replaced by the same solution containing $10 \mu \mathrm{M}$ taurine. Radioactive taurine $(0.1 \mu \mathrm{Ci} / \mathrm{ml})$ was added to the solution on the apical or basal side of the filter to measure the uptake rate on each surface. Preliminary experiments demonstrated that transepithelial leakage or transport of radiolabeled taurine was negligible, and that $\left[{ }^{3} \mathrm{H}\right]-$ and $\left[{ }^{14} \mathrm{C}\right]$ taurine gave the same transport rates in epithelia seeded identically on filters. Therefore, we were able to study uptake at both surfaces of the same epithelium by using different species of tracer simultaneously on each side, e.g., $\left[{ }^{14} \mathrm{C}\right]$ taurine on the apical side and $\left[{ }^{3} \mathrm{H}\right]$ taurine on the basal side. In every experiment, just before the last uptake period ended, aliquots were taken from the solution on both sides of the filter to check for transepithelial leakage. After the final uptake period, to stop uptake and remove extracellular tracer, the filter on its support was dipped three times sequentially in beakers containing $100 \mathrm{ml}$ of ice-cold stop solution (160 mM choline chloride, $5 \mathrm{mM}$ Hepes/Tris buffered to $\mathrm{pH}$ 7.4). Preliminary experiments showed that the wash procedure removed extracellular tracer. The filter with its attached epithelium was then cut out of the filter support with a surgical blade and put into a scintillation vial, where the cells were solubilized overnight in $500 \mu 10.25 \mathrm{~N} \mathrm{NaOH}$. Duplicate aliquots of $20 \mu \mathrm{l}$ were used for protein determination (Bio-Rad Protein Assay kit). $10 \mathrm{ml}$ of Ready Safe (Beckman Instruments, Inc., Fullerton, CA) was added to the remainder of the sample for liquid scintillation counting.

To measure taurine efflux, cells that had been in isotonic or hypertonic defined medium were loaded with radiolabeled taurine in preincubation medium containing $0.1 \mu \mathrm{Ci} / \mathrm{ml}\left[{ }^{3} \mathrm{H}\right]$ taurine (without cold taurine) for $2 \mathrm{~h}$. Cells were rinsed three times in tracer-free preincubation solution (preliminary tests showed that further rinsing did not lower cell-associated counts), transferred to uptake medium free of tracer, and the appearance of radiolabeled taurine was assessed in the medium on both sides of the epithelium. Tracer counts remaining in the epithelium at the end of the efflux period were measured as in the uptake experiments. Efflux into apical and basal solutions was expressed as the percentage of total counts that appeared in the medium on each side. Total counts were calculated as the sum of cell counts after the efflux period plus medium counts on both sides. Although taurine is not 
metabolized by most cells, we determined that the tracer that appeared in the efflux media was taurine rather than a metabolite. An aliquot of efflux medium was spotted on a slica gel plate, and one-dimensional thin-layer chromatography was performed using a mixture of $n$-propanol and ammonium hydroxide (7:3). An autoradiogram of the plate revealed a single spot whose $\mathrm{Rf}(0.38)$ was the same as that of the taurine tracer used to load the cells.

In experiments in which the cells were in hypertonic medium, PBS, preincubation medium, uptake medium, and stop solution were made hypertonic ( $500 \mathrm{mosmol} / \mathrm{kg}$ ) by adding mannitol. To study transport in the absence of sodium, choline was used to replace all sodium. To study the transport dependence on chloride, chloride was replaced by gluconate. When chloride ion was replaced by other anions such as $\mathrm{Br}^{-}$ or $\mathrm{SCN}^{-}$, only the salts of sodium and potassium were substituted because of nonavailability of the other salts. The final chloride concentration in those experiments was $6 \mathrm{mM}$. Preincubation in sodium- or chloride-free solutions and change into uptake or efflux medium followed the same protocol as experiments performed in the presence of sodium or chloride.

Materials. $\left[{ }^{14} \mathrm{C}\right](92.1 \mathrm{mCi} / \mathrm{mmol})$ - and $\left[{ }^{3} \mathrm{H}\right](20.1 \mathrm{Ci} / \mathrm{mmol})$-taurine were purchased from New England Nuclear, Boston, MA. Unlabeled taurine, hypotaurine, and $\beta$-alanine were purchased from Sigma Chemical Co., St. Louis, MO.

Data analysis. The results shown are means \pm SD. When no error bar is shown in a figure, the SD is smaller than the symbol. Statistical significance was determined using analysis of variance (ANOVA) for multiple comparisons or Student's $t$ test for paired comparison. Al experiments presented were performed more than once with similar results.

\section{Results}

Effect of taurine on colony-forming efficiency in hypertonic medium. Colony-forming efficiency was used as a quantitative measure of survival and growth of MDCK cells under various conditions. After allowing $24 \mathrm{~h}$ for cell attachment in isotonic defined medium with $10 \%$ FBS, the medium was switched to isotonic or hypertonic defined medium with $10 \%$ extensively dialyzed serum, with or without $200 \mu \mathrm{M}$ myo-inositol, $100 \mu \mathrm{M}$ betaine, or $50 \mu \mathrm{M}$ taurine. Choline was present in the defined medium, so under all conditions, cells could accumulate glycerophosphorylcholine (32). Results (Table I) are expressed as the percentage of the colony-forming efficiency under control conditions (isotonic medium containing $200 \mu \mathrm{M}$ myo-inositol). We used this condition as the control because MDCK cells were usually grown under those conditions. Removal of myoinositol from the medium or the substitution of betaine or taurine for myo-inositol did not affect colony-forming efficiency in isotonic medium. In contrast, virtually no colonies grew out in hypertonic medium without myo-inositol or betaine. However, the addition to the medium of myo-inositol or betaine, the major osmolytes that have been identified in MDCK cells, increased colony-forming efficiency to $23 \%$ and $38 \%$, respectively. Taurine also increased colony-forming efficiency to $30 \%$, suggesting that taurine is taken up from the medium like myo-inositol and betaine and can act as a compatible osmolyte in MDCK cells.

Taurine content of isotonic and hypertonic cells. If taurine is functioning as a compatible osmolyte, its concentration should be elevated in hypertonic cells. The taurine content of hypertonic cells $48 \mathrm{~h}$ after the medium osmolarity was increased (from 300 to $500 \mathrm{mosmol} / \mathrm{kg}$ ) was $327 \pm 0.6 \mathrm{nmol} / \mathrm{mg}$ protein, about twice the value in isotonic cells $(170 \pm 7.8 \mathrm{nmol} / \mathrm{mg}$ protein, mean $\pm \mathrm{SD}, n=3$ ). When cells were grown in defined
Table I. Colony-forming Efficiency

\begin{tabular}{|c|c|c|c|}
\hline \multicolumn{3}{|c|}{ Medium } & \multirow{2}{*}{$\begin{array}{l}\text { Colony-forming } \\
\text { efficiency }\end{array}$} \\
\hline myo-Inositol & Betaine & Taurine & \\
\hline$\mu M$ & $\mu M$ & $\mu M$ & $\%$ \\
\hline \multicolumn{4}{|c|}{ Isotonic $(300 \mathrm{mosmol} / \mathrm{kg})$} \\
\hline 200 & 0 & 0 & 100 \\
\hline 0 & 0 & 0 & $100 \pm 6.1$ \\
\hline 0 & 100 & 0 & $98 \pm 5.5$ \\
\hline 0 & 0 & 50 & $103 \pm 2.1$ \\
\hline \multicolumn{4}{|c|}{ Hypertonic (500 mosmol/kg) } \\
\hline 0 & 0 & 0 & $3 \pm 2.1$ \\
\hline 200 & 0 & $\mathbf{0}$ & $23 \pm 5.7^{*}$ \\
\hline 0 & 100 & $\mathbf{0}$ & $38 \pm 4.7^{*}$ \\
\hline 0 & 0 & 50 & $31 \pm 6.4^{*}$ \\
\hline
\end{tabular}

Results are mean \pm SD of three separate experiments. Efficiency for the control condition (isotonic with $200 \mu \mathrm{M}$ myo-inositol) was taken as $100 \%{ }^{*} P<0.01$ compared to hypertonic without $m y o$-inositol, betaine, or taurine.

medium without taurine, the taurine content of isotonic and hypertonic cells $48 \mathrm{~h}$ after switching medium osmolarity (from 300 to $500 \mathrm{mosmol} / \mathrm{kg}$ ) were not statistically different $(41.0 \pm 4.4$ and $49.5 \pm 7.8 \mathrm{nmol} / \mathrm{mg}$ protein, respectively, mean $\pm \mathrm{SD}, n=3$ ), suggesting that the increase in taurine content evoked by hypertonicity resulted from increased uptake rather than from increased biosynthesis of taurine.

Taurine transport in isotonic cells. In preliminary experiments, tracer added to one surface was never detected in the solution on the other surface of the epithelium, indicating that within the period of these experiments there was neither transport nor leakage of taurine across the epithelium. Taurine uptake was linear with time on both surfaces for at least 30 min (Fig. 1). Therefore, in subsequent experiments uptake periods of $10 \mathrm{~min}$ were used to estimate initial uptake rates. Taurine was taken up predominantly on the basal side. Over several experiments performed with different platings, taurine uptake on the basal side was about seven times uptake on the apical side. The initial experiments also revealed that there was no uptake of taurine at either surface in sodium-free uptake solution (Fig. 1).

To test whether MDCK cell taurine transport, like that in other cells, is chloride as well as sodium dependent, we replaced external $\mathrm{Cl}^{-}$by gluconate (Table II). Uptake on both sides was almost completely inhibited. The order of anion dependence was $\mathrm{Cl}^{-}>\mathrm{Br}^{-} \geq \mathrm{SCN}^{-}>$gluconate ${ }^{-}$on both sides, with a similar degree of inhibition.

In many tissues, taurine uptake appears to be mediated by a $\beta$-amino acid transporter. The MDCK cell transporter on both apical and basolateral surfaces behaved similarly in that the addition of $2 \mathrm{mM}$ hypotaurine or $\beta$-alanine inhibited uptake of $10 \mu \mathrm{M}$ taurine, whereas $2 \mathrm{mM}$ alanine, an $\alpha$-amino acid did not inhibit taurine uptake (Table III). 4,4'-diisothiocyanatostilbene-2,2'-disulfonic acid (DIDS) inhibited taurine transport in rat renal brush border membrane vesicles (20), but had no effect on taurine uptake by MDCK cells (Table III).

Taurine transport by hypertonic cells. Switching MDCK cells to a hypertonic culture medium elicits a rapid increase in 


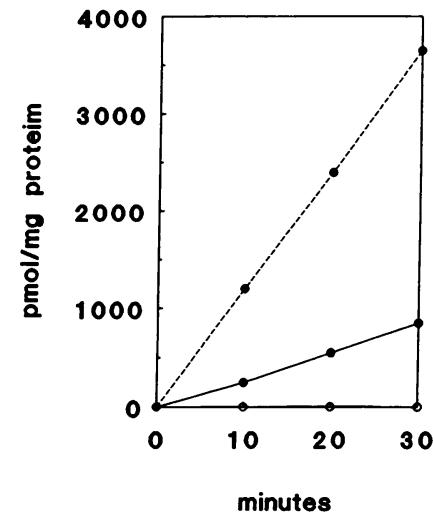

Figure 1. Time course of taurine uptake into MDCK cells. Uptake was performed at $37^{\circ} \mathrm{C}$ in the presence of $10 \mu \mathrm{M}$ taurine. (- - - - - -) Uptake from the basal solution in the presence of $\mathrm{Na}$; ( $-\longrightarrow)$ uptake from the apical solution in the presence of $\mathrm{Na}$; $(-0-)$ apical and basal uptake in the absence of $\mathrm{Na}$ (substituted by choline)

the rate of uptake of the osmolytes myo-inositol and betaine (4, 5 ) across the basolateral surface $(37,38)$. To examine the response of the taurine transporters to hypertonicity, we measured taurine uptake at both surfaces after switching epithelia to medium made hypertonic $(500 \mathrm{mosmol} / \mathrm{kg})$ by addition of raffinose (Fig. $2 A$ ). Increased uptake on the basal surface was evident $16 \mathrm{~h}$ after the switch to hypertonic medium, reaching a peak at $24 \mathrm{~h}$ that was $91 \%$ greater than in isotonic cells. During the second day after the switch, uptake fell to $\sim 40 \%$ more than in isotonic cells and remained at that level. Thus, in hypertonic medium, the activity of the taurine transporter at the basolateral surface of MDCK cells is increased like that of the myo-inositol and betaine transporters. Apical uptake increased minimally in the first $24 \mathrm{~h}$ and then decreased to a lower rate than in matched isotonic cells.

There is an interesting interaction among osmolytes in that poor accumulation of one, because of an inhibitor or the lack of substrate, leads to increased accumulation of some other osmolytes $(5,39)$. To test for that type of behavior for the taurine transporter, we prevented the accumulation of myo-inositol, one of the major osmolytes in MDCK cells (3), by omitting myo-inositol from the medium at the time of the switch to hypertonic medium (Fig. $2 \mathrm{~B}$ ). The culture medium for all experiments contained choline which allows cells to accumulate the osmolyte glycerophosphorylcholine (32). When myoinositol was omitted, the basolateral uptake rate at $24 \mathrm{~h}$ rose about as much as in the presence of myo-inositol but thereafter remained $\sim 90 \%$ higher than in paired controls in isotonic

Table II. Effect of Cation or Anion Replacement on Taurine Uptake

\begin{tabular}{lcc}
\hline & Apical & Basolateral \\
\hline & \multicolumn{2}{c}{ pmol/min $\cdot$ mg protein } \\
$\mathrm{NaCl}$ & $8.5 \pm 0.1(100)$ & $141.3 \pm 0.3(100)$ \\
$\mathrm{Choline} \mathrm{Cl}$ & $0.28 \pm 0.006(3.2)$ & $0.5 \pm 0.1(0.4)$ \\
$\mathrm{Na}$ gluconate $\left(\mathrm{Cl}^{-}=0 \mathrm{mM}\right)$ & $0.32 \pm 0.01(3.8)$ & $2.3 \pm 0.3(1.6)$ \\
$\mathrm{Na}$ gluconate $\left(\mathrm{Cl}^{-}=6 \mathrm{mM}\right)$ & $1.3 \pm 0.04(15)$ & $26.6 \pm 1.0(19)$ \\
$\mathrm{NaBr}\left(\mathrm{Cl}^{-}=6 \mathrm{mM}\right)$ & $3.7 \pm 0.3(44)$ & $53.3 \pm 1.6(38)$ \\
$\mathrm{NaSCN}\left(\mathrm{Cl}^{-}=6 \mathrm{mM}\right)$ & $4.2 \pm 0.04(50)$ & $42.6 \pm 1.6(30)$
\end{tabular}

Values are mean $\pm \mathrm{SD}$. Numbers in parentheses are the percentage of control ( $\mathrm{NaCl}$ value). Uptake was performed at $37^{\circ} \mathrm{C}$ for $10 \mathrm{~min}$ with $10 \mu \mathrm{M}$ taurine.

Table III. Effect of Amino Acids and DIDS on Taurine Uptake

\begin{tabular}{|c|c|c|}
\hline & Apical & Basolateral \\
\hline & \multicolumn{2}{|c|}{ pmol/min $\cdot m g$ protein } \\
\hline Control & $8.5 \pm 0.1(100)$ & $142 \pm 0.3(100)$ \\
\hline Hypotaurine (2 mM) & $0.3 \pm 0.01(3.3)^{*}$ & $2.0 \pm 0.1(1.4)^{*}$ \\
\hline$\beta$-alanine (2 mM) & $0.75 \pm 0.3(8.7)^{*}$ & $10.1 \pm 1.0(7.1)^{*}$ \\
\hline L-alanine (2 mM) & $9.2 \pm 0.1(108)$ & $125 \pm 10.4(88)$ \\
\hline DIDS (0.5 mM) & $9.2 \pm 0.8(107)$ & $144 \pm 3.4(102)$ \\
\hline
\end{tabular}

Values are mean $\pm \mathrm{SD}$. Numbers in parentheses are the percentage of control ( $\mathrm{NaCl}$ value). Uptake was performed at $37^{\circ} \mathrm{C}$ for $10 \mathrm{~min}$ with $10 \mu \mathrm{M}$ taurine in the presence of $2 \mathrm{mM}$ amino acids or inhibitors. ${ }^{*} P<0.01$ compared to control.

medium lacking myo-inositol, as though the accumulation of taurine was compensating for the lack of accumulation of $m y o-$ inositol.

When hypertonic MDCK or HT25 cells were switched back to isotonic medium, the various adaptations that resulted in osmolyte accumulation in cells in hypertonic medium reversed at different rates $(32,33,40)$. When MDCK cells that had been in hypertonic medium for $4 \mathrm{~d}$ were switched to isotonic medium, the rate of taurine uptake on the basolateral side returned to the isotonic level within $16 \mathrm{~h}$ (Fig. 3).

The increase in myo-inositol and betaine uptake in hypertonic cells has been identified as an increase in $V_{\max }(5,33)$. To characterize further the increased rate of taurine uptake in hypertonic cells, we assayed uptake on both surfaces at a variety of concentrations, $24 \mathrm{~h}$ after the switch, when uptake was at its peak. Fig. 4, $A$ and $B$, shows representative Eadie-Hofstee plots of the data. Under isotonic conditions, the $K_{\mathrm{m}}$ of apical transport was $\sim 10 \mu \mathrm{M}$, whereas the $K_{\mathrm{m}}$ on the basal surface was $\sim 50 \mu \mathrm{M}$. The only change evoked by $24-\mathrm{h}$ exposure to a hypertonic medium was a doubling of the $V_{\max }$ for taurine trans-
A

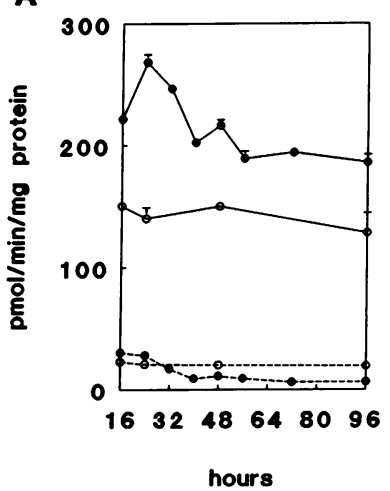

B

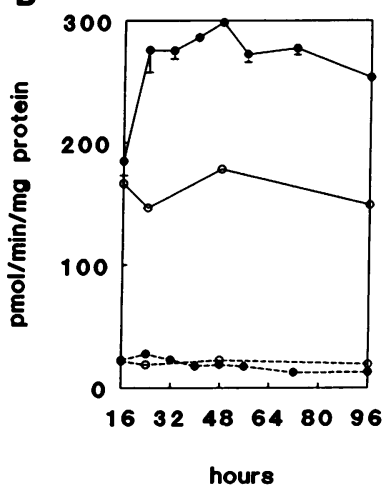

Figure 2. Taurine uptake into MDCK cells after switch into isotonic or hypertonic medium in the $(A)$ presence or $(B)$ absence of $200 \mu \mathrm{M}$ myo-inositol. Uptake rate was measured in $\mathrm{Na}$ uptake solution with $10 \mu \mathrm{M}$ taurine at $37^{\circ} \mathrm{C}$ for $10 \mathrm{~min}$. Results are means $\pm \mathrm{SD}$. (- - - - - ) Uptake from the apical solution by cells in isotonic medium; (- - - - -) uptake from the apical solution by cells in hypertonic medium; (- - - uptake from the basal solution by cells in isotonic medium; ( $-\bullet$ ) uptake from the basal solution by cells in hypertonic medium. 


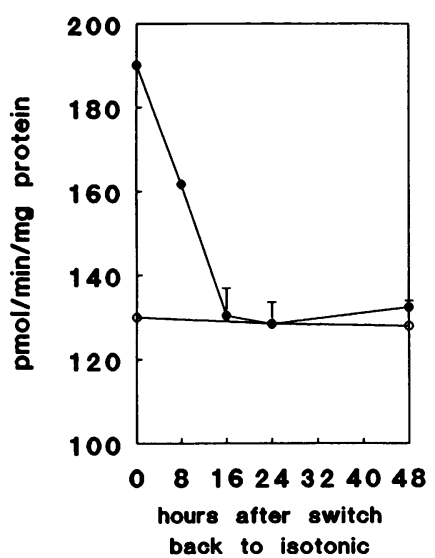

Figure 3. Taurine uptake after the switch of hypertonic cells to isotonic medium. Uptake rate was measured in $\mathrm{Na}$ uptake solution with $10 \mu \mathrm{M}$ taurine at $37^{\circ} \mathrm{C}$ for $10 \mathrm{~min}$. (—o- - Uptake from the basal solution by control cells in isotonic medium;

$(-\bullet-)$ uptake from the basal solution by cells switched at time 0 from hypertonic to isotonic medium.

port on the basal side of the epithelium. There was no change in $K_{\mathrm{m}}$ on either surface, and no change in $V_{\max }$ for taurine transport on the apical surface.

Suppression of taurine transport in medium containing taurine. When MDCK cells are cultured on plastic tissue culture dishes in defined medium lacking taurine, their rate of uptake of taurine is increased to two times the rate in cells grown in defined medium containing $50 \mu \mathrm{M}$ taurine (12). To examine the polarity of the effect of medium taurine on taurine uptake, we added $50 \mu \mathrm{M}$ taurine to the medium $2 \mathrm{~d}$ after seeding cells on filters. We cultured other cells seeded at the same time in the usual defined medium that does not contain taurine. The omission of taurine from the medium resulted in a tripling of the rate of taurine uptake on both apical and basal surfaces (Fig. 5). Hypertonicity in the continued presence of taurine elicited increased taurine uptake that was about twice the lower rate in isotonic cells maintained in medium containing taurine (Fig. 5). The increase in uptake in response to hypertonicity was again evident only on the basal surface.

Taurine is rapidly lost when cells are switched from hypertonic to isotonic solution. When MDCK cells or HT-25 cells
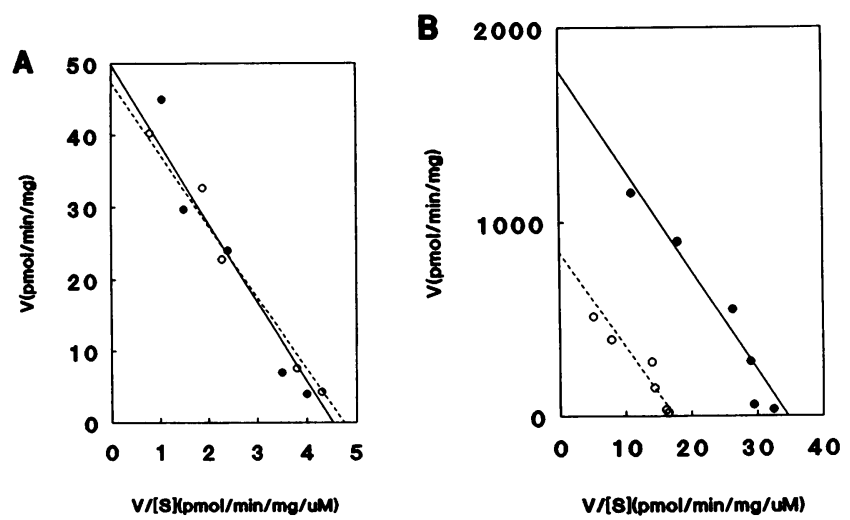

Figure 4. Eadie-Hofstee plot of taurine uptake into MDCK cells from $(A)$ apical solution and $(B)$ basal solution. Uptake rate was measured 1 day after switching medium osmolarity. ( $-\longrightarrow$ ) Uptake in hypertonic medium. (-- $-0---)$ Uptake in isotonic medium. $(A)$ $K_{\mathrm{m}}=10.5 \mu \mathrm{M}, V_{\max }=49.5 \mathrm{pmol} / \mathrm{min} \cdot \mathrm{mg}$ protein in isotonic medium and $12.7 \mu \mathrm{M}$ and $50.5 \mathrm{pmol} / \mathrm{min} \cdot \mathrm{mg}$ protein in hypertonic medium, respectively. $(B) K_{\mathrm{m}}=55.7 \mu \mathrm{M}, V_{\max }=932.7 \mathrm{pmol} /$ $\mathrm{min} \cdot \mathrm{mg}$ protein in isotonic medium and $53.2 \mu \mathrm{M}$ and $1748.0 \mathrm{pmol} /$ $\mathrm{min} \cdot \mathrm{mg}$ protein in hypertonic medium, respectively.

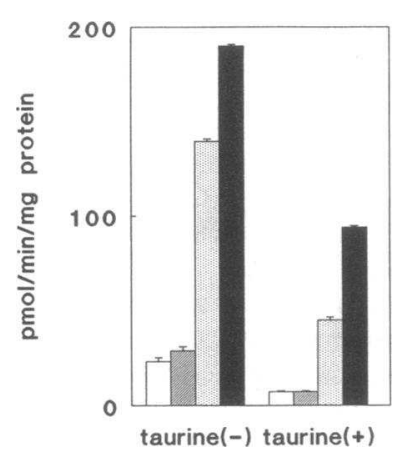

Figure 5. Effect of taurine in the culture medium on the up-regulation of taurine uptake by hypertonicity. MDCK cells were maintained in defined media with or without $50 \mu \mathrm{M}$ taurine for $5 \mathrm{~d}$, then switched into isotonic or hypertonic media with or without 50 $\mu \mathrm{M}$ taurine. $16 \mathrm{~h}$ after switching medium osmolarity, uptake rate was measured in Na uptake solution containing $10 \mu \mathrm{M}$ taurine. Results are mean \pm SD of triplicate samples. (Open bars) Uptake from the apical solution by cells in isotonic medium; (hatched bars) uptake from the apical solution by cells in hypertonic medium; (stippled bars) uptake from the basal solution by cells in isotonic medium; (filled bars) uptake from the basal solution by cells in hypertonic medium.

that have adapted to a hypertonic medium are shifted to an isotonic medium, they rapidly release a considerable portion of their accumulated osmolytes $(33,41)$. The release of osmolytes minimizes cell swelling. To examine the behavior of MDCK cell taurine under those conditions, we loaded cells with radiolabeled taurine for $2 \mathrm{~h}$ under isotonic or hypertonic conditions before rinsing the cells free of extracellular tracer and measuring efflux of tracer when cells were transferred to a hypertonic or isotonic solution. Fig. 6 shows the results of the efflux studies. Virtually no efflux was observed on either side when medium osmolarity was not changed $(500 \rightarrow 500$ or $300 \rightarrow 300$ mosmol $/ \mathrm{kg}$ ). However, when cells in hypertonic medium were transferred to isotonic medium, $>20 \%$ of total tracer was released within $10 \mathrm{~min}$, and another 5-10\% was released over the next $50 \mathrm{~min}$. Almost all released taurine appeared in the medium on the basal side.

\section{Discussion}

We have demonstrated that taurine can function as a nonperturbing osmolyte in MDCK cells, a role suggested for taurine in the renal medulla (30) and some other tissues $(17,25,28)$. We found that the presence of physiologic concentrations of taurine or either of the well-established MDCK cell osmolytes,
A

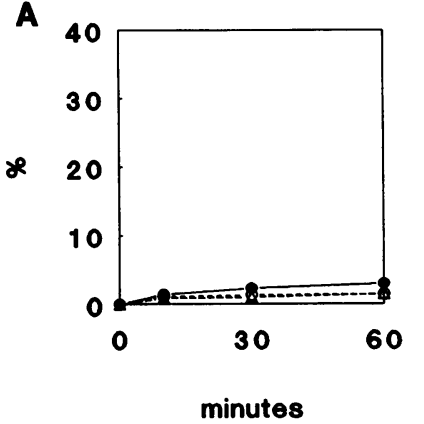

B

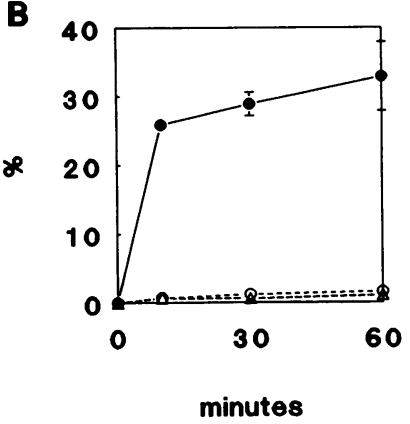

Figure 6. Efflux of taurine from MDCK cells into $(A)$ apical solution and $(B)$ basal solution. Experiments were performed $24 \mathrm{~h}$ after cells were shifted to hypertonic medium. Results are mean \pm SD of triplicate samples. (- - $0---)$ Isotonic to isotonic. $(---\Delta---)$ Hypertonic to hypertonic. ( $-\longrightarrow)$ Hypertonic to isotonic. 
myo-inositol or betaine, supported clonal growth at similar rates. As predicted, the taurine content of MDCK cells increased after cells were switched to hypertonic medium. The difference in taurine content between isotonic and hypertonic cells was $\sim 160 \mathrm{nmol} / \mathrm{mg}$ protein, which corresponds to $\sim 60$ $\mathrm{mM}$ in terms of intracellular concentration (3). The increase in taurine content was completely dependent on medium taurine. Therefore we studied how taurine is accumulated and released when medium osmolarity is changed.

We found that MDCK cells have taurine transporters on both sides of the epithelium. Tracer added to one side did not appear on the other side of the epithelium, indicating that the taurine transporters in MDCK cells function to take taurine up into cells from solutions analogous to urine and blood rather than for transepithelial absorption or secretion.

Sodium and chloride dependence are apparently universal characteristics of taurine transporters $(12,13,17,18,20)$. Our observations were similar: taurine transport at both surfaces depended on the presence of sodium and chloride (Table II). The substitution of choline for sodium or gluconate ${ }^{-}$for $\mathrm{Cl}^{-}$ almost completely inhibited taurine uptake on both surfaces. Also, the taurine transporter at both surfaces was like those described in other tissues $(9,10,13-15)$ in that taurine uptake was inhibited by $\beta$-amino acids, hypotaurine and $\beta$-alanine, but not by an $\alpha$-amino acid, L-alanine. We did not determine the apparent affinity of the transporter for other $\beta$-amino acids compared to its affinity for taurine. A specific inhibitor for this transport system has not been identified. Because anion cotransport is characteristic of taurine transport, DIDS $(0.5 \mathrm{mM})$ was tested and found to inhibit taurine uptake in rat renal brush border membrane vesicles (20). DIDS had no effect in our experiments.

Although the characteristics of taurine transport on both sides of the MDCK epithelium are similar in terms of sodium and anion dependence and the effects of inhibitors, the transporters on each surface are apparently not the same. The affinity for taurine was much higher on the apical surface than on the basal surface and the uptake rate on the apical surface was about one-seventh the rate on the basal surface. Both transporters serve to accumulate taurine in cells. Previously reported affinities for taurine are $6 \mu \mathrm{M}$ in membrane vesicles from human placenta (13), $25 \mu \mathrm{M}$ in rat renal brush border membrane vesicles (20), and $50 \mu \mathrm{M}$ in MDCK cells grown on plastic tissue culture dishes (12). The last is similar to that we found at the basal surface of MDCK cells grown on filters. Plasma taurine is $\sim 50 \mu \mathrm{M}(8)$.

Taurine is accumulated during hypertonicity or released during shift to lower osmolarity by tissues in fish $(14,21,27)$, by Ehrlich ascites tumor cells $(15,17)$, and in most (23-25), but not all (26) studies of rat brain. In this study we found that taurine uptake and release by MDCK cells was regulated by medium osmolarity. Hypertonicity increased uptake only on the basal surface. Kinetic assays indicated that the effect was an increase in $V_{\max }$ without change in $K_{\mathrm{m}}$. The transporters for two other osmolytes (myo-inositol and betaine) that are located exclusively on the basal surface of MDCK cells (37) also manifested increased $V_{\max }$ in response to hypertonicity $(4,5)$. This response is probably explained by an increase in the number of transporters for each osmolyte. The increase may well be the result of increased levels of mRNA for each transporter since injection of poly $(\mathrm{A})^{+} \mathrm{RNA}$ from hypertonic MDCK cells into Xenopus oocytes results in higher rates of uptake of myo-inosi- tol (42), betaine (43), and taurine (44) than injection of similar amounts of poly(A) ${ }^{+}$RNA from isotonic MDCK cells. Unfortunately, we were unable to test for inhibition of the response to hypertonicity by inhibitors such as actinomycin D or cycloheximide because of their general toxicity on MDCK cells under the conditions of our experiments.

It is likely that there is a common factor or event at some point in the response to hypertonicity that regulates the accumulation of osmolytes, in that when the accumulation of one is impaired there is a compensatory increase in the accumulation of another (39). We feel that the maintenance of high levels of taurine transporter activity in hypertonic cells that cannot accumulate myo-inositol because of its absence from the culture medium (Fig. $2 \mathrm{~B}$ ) reflects such an interaction between the accumulation of taurine and myo-inositol, and supports the suggestion that taurine functions as an osmolyte in MDCK cells. Further support for the suggestion is the similar pattern of efflux of taurine and the established osmolytes when hypertonic cells were shifted to isotonic medium. Like the other osmolytes, the accumulation of taurine increases slowly when cells are shifted to a hypertonic medium, and the loss of taurine occurs rapidly when cells are switched from hypertonic to isotonic medium.

Just as deprivation of taurine from the diet results in up-regulation of the taurine transporter in renal brush border membrane vesicles, removal of taurine from the culture medium resulted in up-regulation of taurine transport by MDCK and by LLC-PK1 cells grown on plastic tissue culture dishes (12). We found that in contrast to the effect of hypertonicity, which increased uptake only on the basal surface, removal of taurine from the medium increased uptake on both apical and basal surfaces. Similar observations have been reported in preliminary form (45). The effect of hypertonicity on basolateral uptake was apparent in the presence or absence of medium taurine (Fig. 5). The lower rate of uptake in cells cultured in medium containing taurine presumably reflects feedback signaling from cell taurine.

The effect of hypertonicity on taurine transport in MDCK cells resembles its effect on myo-inositol and betaine transport. In cells on filters, the effect is solely on uptake at the basal surface, peaks at $24 \mathrm{~h}$, and when hypertonicity is reversed, the rapid efflux also occurs at the basal surface $(37,38)$. In medullary tubules, uptake would be possible only at the basal surface since almost all filtered myo-inositol, betaine, and taurine is reabsorbed proximally $(11,46,47)$. Release of osmolytes across that surface in medullary tubules would conserve taurine for the organism.

\section{References}

1. Bagnasco, S., R. Balaban, H. Fales, Y.-M. Yang, and M. B. Burg. 1986. Identification of intracellular organic osmolytes in renal inner medulla. J. Biol. Chem. 261:5872-5877.

2. Yancy, P. H., M. E. Clark, S. C. Hand, R. D. Bowlus, and G. N. Somero. 1982. Living with water stress:evolution of osmolyte systems. Science (Wash. DC). 217:1214-1222.

3. Nakanishi, T., R. S. Balaban, and M. B. Burg. 1988. Survey of osmolytes in renal cell lines. Am. J. Physiol. 255:C181-C191.

4. Nakanishi, T., R. J. Turner, and M. B. Burg. 1989. Osmoregulatory changes in myo-inositol transport by renal cells. Proc. Natl. Acad. Sci. USA. 86:6002-6006.

5. Nakanishi, T., R. J. Turner, and M. B. Burg. 1990. Osmoregulation of betaine transport in mammalian renal medullary cells. Am. J. Physiol. 258:F1061-F1067. 
6. Chesney, R. W. 1985. Taurine: its biological role and clinical implications. Adv. Pediatr. 1-42.

7. Huxtable, R. J., and S. E. Lippincott. 1982. Relative contribution of diet and biosynthesis to the taurine content of the adult rat. Drug-Nutr. Interact. 1:153-168.

8. Palmerini, C. A., C. Fini, M. G. Cantelmi, and A. Floridi, 1987. Assessment of taurine in plasma and urine by anion-exchange high-performance liquid chromatography with pre-column derivatization. J. Chromatogr. 423:292-296.

9. Barnard, J. A., S. Thaxter, K. Kikuchi, and F. K. Ghishan. 1988. Taurine transport by rat intestine. Am. J. Physiol. 254:G334-G338.

10. Bucuvalas, J. C., A. L. Goodrich, and F. J. Suchy. 1987. Hepatic taurine transport: a $\mathrm{Na}^{+}$-dependent carrier on the basolateral plasma membrane. Am. $J$. Physiol. 253:G351-G358.

11. Dantzler, W. H., and S. Silbernagl. 1976. Renal tubular reabsorption of taurine, $\gamma$-aminobutyric acid (GABA) and $\beta$-alanine studied by continuous microperfusion. Pflügers Arch. 367:123-128.

12. Jones, D. P., L. A. Miller, and R. W. Chesney. 1990. Adaptive regulation of taurine transport in two continuous renal epithelial cell lines. Kidney Int. 38:219-226.

13. Karl, P. I., and S. E. Fisher. 1990. Taurine transport by microvillous membrane vesicles and the perfused cotyledon of the human placenta. Am.J. Physiol. 258:C443-C451.

14. King, P. A., K. W. Beyenbach, and L. Goldstein. 1982. Taurine transport by isolated flounder renal tubules. J. Exp. Zool. 223:103-114.

15. Lambert, I. H. 1984. $\mathrm{Na}^{+}$-dependent taurine uptake in Ehrlich ascites tumour cells. Mol. Physiol. 6:233-246.

16. Meiners, B. A., R. C. Speth, N. Bresolin, R. J. Huxtable, and H. I. Yamamura. 1980. Sodium-dependent, high-affinity taurine transport into rat brain synaptosomes. FASEB (Fed. Am. Soc. Exp. Biol.) J. 39:2695-2700.

17. Lambert, I. H. 1985. Taurine transport in Ehrlich ascites tumour cells specificity and chloride dependence. Mol. Physiol. 7:323-332.

18. Turner, R. J. 1988. $\beta$-Amino acid transport across the renal brush-borde membrane is coupled to both $\mathrm{Na}$ and $\mathrm{Cl}$. J. Biol. Chem. 261:16060-16066.

19. Wolff, N. A., and R. Kinne. 1988. Taurine transport by rabbit brushborder membranes: coupling to sodium, chloride, and membrane potential. $J$. Membr. Biol. 102:131-139.

20. Zelikovic, I., E. Stejskal-Lorenz, P. Lohstroh, A. Budreau, and R. W. Chesney. 1989. Anion dependence of taurine transport by rat renal brush-border membrane vesicles. Am. J. Physiol. 256:F646-F655.

21. Wolff, N. A., D. F. Perlamn, and L. Goldstein. 1986. Ionic requirements of peritubular taurine transport in Fundulus kidney. Am. J. Physiol. 250:R984R990.

22. Chesney, R. W., N. Gusowski, and S. Dabbagh. 1985. Renal cortex taurine content regulates renal adaptive response to altered dietary intake of sulfur amino acids. $J$. Clin. Invest. 76:2213-2221.

23. Trachtman, H., R. Barbour, J. A. Sturman, and L. Finberg. 1988. Taurine and osmoregulation: taurine is a cerebral osmoprotective molecule in chronic hypernatremic dehydration. Pediatr. Res. 23:35-39.

24. Wade, J. V., J. P. Olson, F. E. Samson, S. R. Nelson, and T. L. Pazdernik 1988. A possible role for taurine in osmoregulation within brain. J. Neurochem. 51:740-745.

25. Lien, Y-H. H., J. I. Shapiro, and L. Chan. 1990. Effects of hypernatremia on orgainic brain osmoles. J. Clin. Invest. 85:1427-1435.

26. Heilig, C. W., M. E. Stromski, J. D. Blumenfeld, J. P. Lee, and S. R. Gullans. 1989. Characterization of the major brain osmolytes that accumulate in salt-loaded rats. Am. J. Physiol. 257:F1108-F1116.

27. King, P. A., and L. Goldstein. 1983. Organic osmolytes and cell volume regulation in fish. Mol. Physiol. 4:53-66.
28. Schrock, H., R. P. Forster, and L. Goldstein. 1982. Renal handling of taurine in marine fish. Am. J. Physiol. 242:R64-R69.

29. Goldstein, L., S. R. Brill, and E. V. Freund. 1990. Activation of taurine efflux in hypotonicity stressed elasmobranch cells: inhibition by stilbene disulfonates. J. Exp. Zool. 254:114-118.

30. Nakanishi, T., T. Yamada, T. Iida, O. Uyama, and M. Sugita. 1990 Amino acids also accumulated in rat renal medulla during antidiuresis. Proc. XIth Int. Congr. Nephrol. 503A. (Abstr.)

31. Taub, M., L. Chuman, M. H. Saier, Jr., and G. Sato. 1979. Growth of Mardin-Darby canine kidney epithelial cell (MDCK) line in hormone-supplemented, serum-free medium. Proc. Natl. Acad. Sci. USA. 76:3338-3342.

32. Nakanishi, T., and M. B. Burg. 1989. Osmoregulation of glycerophosphorylcholine content of mammalian renal cells. Am. J. Physiol. 257:C795C801.

33. Nakanishi, T., and M. B. Burg. 1989. Osmoregulatory fluxes of myo-inositol and betaine in renal cells. Am. J. Physiol. 257:C964-C970.

34. Yancey, P. H., and M. B. Burg. 1990. Counteracting effects of urea and betaine in mammalian cells in culture. Am. J. Physiol. 258:R198-R204.

35. Yancey, P. H., M. B. Burg, and S. M. Bagnasco. 1990. Effects of NaCl, glucose, and aldose reductase inhibitors on cloning efficiency of renal medullary cells. Am. J. Physiol. 258:C156-C163.

36. Moriyama, T., A. Garcia-Perez, A. D. Olson, and M. B. Burg 1991. Intracellular betaine substitutes for sorbitol in protecting renal medullary cells from hypertonicity. Am. J. Physiol. 260:F494-F497.

37. Yamauchi, A., H. M. Kwon, S. Uchida, A. S. Preston, and J. S. Handler. 1990. The myo-inositol transporters regulated by tonicity are basolateral in cultured kidney (MDCK) cells. Clin. Res. 38:274A. (Abstr.)

38. Yamauchi, A., H. M. Kwon, A. S. Preston, and J. S. Handler. 1990. The betaine transporters regulated by tonicity are basolateral in cultured kidney (MDCK) cells. J. Am. Soc. Nephrol. 1:710. (Abstr.)

39. Moriyama, T., A. Garcia-Perez, and M. B. Burg. 1990. Factors affecting the ratio of the different organic osmolytes in renal medullary cells. Am. J. Physiol. 259:F847-F858.

40. Garcia-Perez, A., B. Martin, H. R. Murphy, S. Uchida, H. Murer, B. D. Cowley, Jr., J. S. Handler, and M. B. Burg. 1989. Molecular cloning of cDNA coding for kidney aldose reductase. J. Biol. Chem. 264:16815-16821.

41. Siebens, A. W., and K. R. Spring. 1989. A novel sorbitol transport mechanism in cultured renal papillary epithelial cells. Am. J. Physiol. 257:F937-F946.

42. Kwon, H. M., A. Yamauchi, S. Uchida, R. B. Robey, A. Garcia-Perez, M. B. Burg, and J. S. Handler. 1991. Renal $\mathrm{Na}^{+} /$myo-inositol cotransporter mRNA expression in Xenopus oocytes: regulation by hypertonicity. Am. J. Physiol. 260:F258-F263.

43. Robey, R. B., D. E. Ellis, H. M. Kwon, J. S. Handler, A. Garcia-Perez, and M. B. Burg. 1990. Expression of $\mathrm{Na}^{+}$-dependent betaine uptake in Xenopus oocytes injected with mRNA from osmotically-stressed MDCK cells. J. Am. Soc Nephrol. 1:705. (Abstr.)

44. Uchida, S., H. M. Kwon, A. S. Preston, and J. S. Handler. 1991. Expression of MDCK cell $\mathrm{Na}^{+}, \mathrm{Cl}^{-}$-dependent taurine transporter in Xenopus laevis oocytes. J. Biol. Chem. 266:9605-9609.

45. Jones, D. P., L. A. Miller, and R. W. Chesney. 1990. Asymetric polarity of taurine transport in cultured renal epithelium. J. Am. Soc. Nephrol. 1:701. (Abstr.)

46. Hammerman, M. R., B. Sacktor, and W. H. Daughaday. 1980. Myo-inositol transport in renal brush border vesicles and its inhibition by D-glucose. $\mathrm{Am}$. J. Physiol. 239:F113-F120.

47. Wright, S. H., and T. M. Wunz. 1989. Na-dependent betaine transport in renal brush border membrane vesicles (BBMV). FASEB (Fed. Am. Soc. Exp. Biol.) J. 3:A858. (Abstr.) 